\title{
Changes in symptoms, peak expiratory flow, and sputum flora during treatment with antibiotics of exacerbations in patients with chronic obstructive pulmonary disease in general practice
}

Alfred P E Sachs, Gerard H Koëter, Klaas H Groenier, Dirk van der Waaij, Janette Schiphuis, Betty Meyboom-de Jong

\begin{abstract}
Background - Bacterial infections of the lower airways during an exacerbation in patients with asthma or chronic obstructive pulmonary disease (COPD) may be the cause of an exacerbation or the consequence of a viral infection or an increase in airways limitation. To determine whether bacterial infection is an important component in the pathogenesis of an exacerbation, the effects of antimicrobial treatment must be studied.
\end{abstract}

Methods - Patients with asthma or COPD seen in general practice were studied in a double blind randomised manner to investigate whether the antimicrobial drugs amoxicillin (500 $\mathrm{mg}$ three times daily), cotrimoxazole ( $960 \mathrm{mg}$ twice daily), or a placebo, each when added to a short course of oral corticosteroids, can accelerate recovery from exacerbations. Patients were instructed to contact their own physician early in the morning when complaints of increased shortness of breath, wheezing, or exacerbations of cough with or without sputum production occurred. Treatment effects were evaluated over the next 14 days by studying symptom scores (wheeze, dyspnoea, cough with and without mucus production, and awakening with dyspnoea), peak expiratory flow values (PEF, expressed as \% predicted), and sublingual temperature. Bacteriological study of the sputum was made at the onset of an exacerbation and 7, 21 and 35 days afterwards.

Results - Of 195 patients enrolled 71 (36\%) contacted their physician for symptoms of an exacerbation. Symptoms improved in all three groups, improvements ranging from 0.54 to 0.75 points per day on a four point scale. PEF \% predicted showed improvements in the three groups after the exacerbation, ranging from $0.34 \%$ to $0.78 \%$ predicted per day, finally returning to baseline values. Sublingual temperature did not change. Six of 71 patients consulted their physician because of a relapse between four and 24 days after the start of treatment. In only two of the 50 sputum samples, collected during an exacerbation, and which contained $\geqslant 10^{5}$ bacteria in cul- ture sensitive to the chosen antibiotic given, did any benefit from antimicrobial treatment occur. During the recovery period sputum purulence improved irrespective of antibiotic treatment.

Conclusions - Antibiotics given with a short course of oral prednisolone during an exacerbation do not accelerate recovery as measured by changes in peak flow and symptom scores in ambulatory patients with mild to moderate asthma or COPD when treated by their general practitioners. Moreover, antibiotics do not reduce the number of relapses after treating an exacerbation.

(Thorax 1995;50:758-763)

Keywords: asthma, COPD, general practice, antibiotics, exacerbation

Exacerbations in patients with asthma or chronic obstructive pulmonary disease (COPD) involve a worsening of symptoms such as dyspnoea and cough, often with purulent sputum. These patients usually receive antimicrobial treatment in combination with a short course of prednisolone, which is the standard treatment for exacerbations of asthma and COPD in the Netherlands. However, the alleged bacterial infection of the lower airways during the exacerbation might be the cause of the exacerbation, or the consequence of a viral infection or the increase in airways limitation. In many studies ${ }^{14}$ which have included microbiological evaluation, including viral and bacteriological cultures and serological assays, a correlation has been observed between the purulence of sputum and the occurrence of an exacerbation.

To obtain evidence of the involvement of bacterial infections of the lower airways during exacerbations of asthma or COPD the effect of antibiotic treatment needs to be evaluated. In 1975 Tager and Speizer ${ }^{5}$ concluded that antibiotic therapy has no clear short term or long term benefit. In a placebo controlled study with amoxicillin, co-trimoxazole, and doxycycline, the use of antibiotic treatment was justified in exacerbations characterised by the triad of increased dyspnoea, sputum production, and purulence. ${ }^{6}$ As no serological or bacteriological monitoring was undertaken in 
most of these studies, ${ }^{17-10}$ it is unclear whether the definition of an exacerbation requires the inclusion of change in sputum colour and also if it is related to a bacteriologically proven infection.

Most studies on the effects of antibiotics on an exacerbation have been assessed by sputum purulence or its quantity. ${ }^{136911-20}$ None of these studies has included bacteriological measurements from either stable and symptomatic phases of asthma or COPD. Furthermore, intervention studies have yielded inconclusive results for the value of antibiotics on symptom scores and peak flow measurements.

We therefore performed a placebo controlled study to assess whether additional treatment with amoxicillin or co-trimoxazole, combined with a short course of prednisolone, accelerated recovery from an acute exacerbation of either asthma or COPD. Bacteriological examination of the sputum samples was made both during and outside exacerbations.

\section{Methods}

PATIENTS

Ambulatory patients with asthma or COPD from 25 general practices in Groningen were informed about the study. Inclusion criteria included age 18 years or older and a positive diagnosis of asthma or COPD made by a pulmonary physician during the previous 10 years. Exclusion criteria included daily use of oral corticosteroids or antimicrobial drugs, diabetes mellitus, alcoholism, history of pulmonary surgery or tuberculosis, severe bronchiectasis, or a psychiatric history. Informative group sessions were conducted by the investigator together with a pulmonary physician, and the patient's general practitioner and assistant. All patients used their normal maintenance medication (inhaled corticosteroids with or without $\beta_{2}$ sympathomimetics) throughout the study.

The study was approved by the medical ethics committee of the University Hospital of Groningen and all patients gave informed consent.

\section{STUDY DESIGN}

Patients with asthma or COPD were instructed to contact their physician, as they would normally do, early in the morning when increased shortness of breath, wheezing, or exacerbations of cough, with or without sputum, occurred. An exacerbation was patient initiated and defined as a sustained increase in dyspnoea with or without sputum production, despite increasing their normal twice daily inhaled therapy to 3-4 times daily. A seven day course of either amoxicillin (500 mg three times daily), co-trimoxazole (960 mg twice daily), or placebo tablets was given in a randomised, double blind manner. Since co-trimoxazole was given twice daily, a third placebo tablet was added to the daily medication. Placebo tablets were given three times daily and tasted either like amoxicillin or co-trimoxazole, maintaining the double blind nature of the trial. As prednisolone
( $35 \mathrm{mg}$ on day 1 , reduced by $5 \mathrm{mg}$ daily) during an exacerbation is the standard treatment prescribed by most physicians in the Netherlands for asthma and COPD, it was used as well. During the following 14 days symptom scores and peak expiratory flow (PEF) values were monitored. Bacteriological examination of sputum samples was made at the onset of an exacerbation and 7, 21, and 35 days afterwards.

\section{Peak expiratory flow}

Daily recordings of $\mathrm{PEF}^{21}$ were made during a seven day baseline period and for two weeks from the start of the exacerbation using a Wright peak flow minimeter (Clement Clarke International, London, UK). Each patient recorded three successive measurements three times per day - early in the morning, before and after their first inhalation medication, and before their second inhalation medication in the evening. The highest outcome of three successive efforts in the morning, before the daily medication, was recorded for analysis.

\section{Treatment failures}

Criteria for treatment failure were revisits to the physician with worsening symptoms within 35 days of the start of treatment. The patient's physician had to decide, if bacterial infection was suspected, whether antimicrobial treatment would be justified based on clinical history and PEF values.

\section{Symptoms}

The following systems were recorded daily by the patient during a two week period on a four point scale of severity ranging from 0 to 3: (1) wheeze or dyspnoea; (2) cough with mucus production; (3) cough without mucus production; and (4) awakening with complaints of dyspnoea. These results were compared with those obtained when stable before the study.

\section{Temperature}

Sublingual body temperature was measured with a Philips thermometer (type HP 6315) at each visit, starting at baseline.

\section{Bacteriology}

Sputum was collected in a vial and taken to the laboratory for microscopic investigation and culture within two hours after expectoration. One washed fragment of each sample was inoculated onto blood agar and Levinthal agar plates for semiquantitative evaluation. The macroscopic appearance was recorded as: watery; mucoid, mucopurulent; or purulent. ${ }^{22}$ The macroscopic appearance and the Gram stain were examined by the same technician and physician during the entire study. "Viridans streptococci" (not further identified $\alpha$-haemolytic streptococci) were regarded as "oropharyngeal flora" as they make up the main proportion of the oropharyngeal flora. ${ }^{22-25}$ 

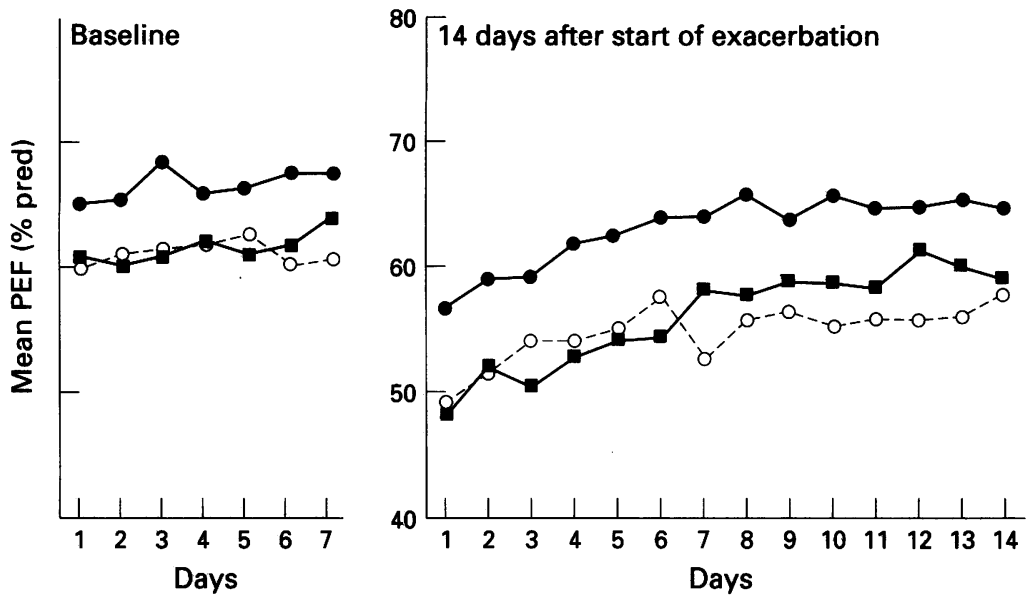

Figure 1 Mean morning peak expiratory flow rates (PEF, \% pred) during baseline and 14 days after exacerbation. $=$ Amoxicillin $(n=22) ; \square=$ co-trimoxazole $(n=17)$; $\mathrm{O}=$ placebo $(n=16)$, all administered in combination with prednisolone.

Gram stain

The same washed pus flake $226-28$ taken for inoculation onto the media was used for microscopic examination after Gram staining. An estimation was made of the number of epithelial cells, leucocytes and bacteria, according to the findings of Murray and Washington ${ }^{23}$ and Heineman et al. ${ }^{29}$ Leucocytes were classified as $<25$ and $\geqslant 25$, bacteria as $<10$ and $\geqslant 10$, both per microscopic field. Epithelial cells were classified as either $<5$ or $\geqslant 5$ per microscopic field. Only specimens with $<5$ epithelial cells per microscopic field were analysed.

STATISTICAL ANALYSIS

Statistical analyses were performed using the $\chi^{2}$ test and the Fisher's exact test to test relationships in cross tables. Pearson correlations and Cronbach's alpha were computed for the symptom scores. Following the suggestion of Matthews et $a l,{ }^{30}$ individual regression coefficients for the changes in PEF and symptom scores were estimated and analysed using the BDMP $5 \mathrm{~V}$ analysis of variance program. ${ }^{31}$ The increase in PEF values and decrease in the symptom severity scores during the 14 consecutive days following the start of the exacerbation was modelled as a linear function of time with an individual slope and intercept. Their expectations equal the slope and intercept of the corresponding treatment group. A value of $p<0.05$ was considered significant. All values are expressed as mean (SD) unless stated otherwise. Using a significance level of 0.05 and a power of 0.80 , the number of patients used in the analysis enabled us to detect a difference in means (symptom scores PEF values as \% predicted) between the antibiotic groups and the placebo group of $1 \mathrm{SD}$. A difference of $0.33 \mathrm{SD}$ could be detected in the mean PEF values measured at different time points within each group, assuming a correlation coefficient of 0.9 between consecutive measures. A difference in symptom scores of $0.66 \mathrm{SD}$ within each group could be detected, assuming a correlation coefficient of 0.55 between consecutive measures.

\section{Results}

One hundred and ninety five patients entered the study between October 1988 and May 1991 , and 71 (36\%), of whom 30 were men, visited their physician because of an exacerbation before March 1992. Their mean (SD) age was $51.7(16.3)$ years, mean PEF $285.3(99.2) 1 / \mathrm{min}$. There were $29(40.9 \%)$ current smokers and $20(28 \cdot 2 \%)$ ex-smokers, median (range) pack years 16.5 (0.15-77). Ten participants were classified as having asthma and 61 COPD. Twenty six patients were randomised to the amoxicillin group, 20 patients to co-trimoxazole, and 25 patients to placebo. No significant differences in patient characteristics between the 71 patients with and the 124 patients without an exacerbation during the study period were observed.

Peak expiratory flow

PEF values were recorded for seven days in the baseline period by 165 of the 195 patients. Of the 71 patients with an exacerbation, 22 of 26 patients in the amoxicillin group, 17 of 20 patients in the co-trimoxazole group, and 16 of 25 patients in the placebo group recorded their PEF levels during the 14 days from the start of an exacerbation. Mean PEF \% predicted values (for each treatment group) of the daily recorded morning peak flow are presented in fig 1. PEF \% predicted values, as a mean of the seven day period of baseline, at the first day of an exacerbation, and at day 14 of an exacerbation are presented in table 1 . PEF values on the first day of an exacerbation were significantly lower than baseline values $(p<0.001)$, but did not differ significantly between the three groups either on the first day of exacerbation or during the following 14 days. The slopes of the PEF values per day (expressed as \% predicted) over the 14 days after the start of the exacerbation and their $95 \%$ confidence intervals are shown in table 2 . A mean daily increase in PEF of $0.68(1.01) \%$ predicted in both groups receiving antibiotics and 0.34 $(0.84) \%$ predicted daily in the placebo group was found. The increase in PEF was significant in all groups $(p<0.001)$, without differences between the groups.

Table 1 Mean (SD) percentage predicted values of peak expiratory flow (PEF) in the three treatment groups

\begin{tabular}{llll}
\hline $\begin{array}{l}\text { Treatment } \\
\text { groups }\end{array}$ & $\begin{array}{l}\text { Mean of } 7 \text { day } \\
\text { baseline period }\end{array}$ & Day 1 & Day 14 \\
\hline Amoxicillin & $66.7(22.1)$ & $56.7(20 \cdot 5)$ & $64.9(24 \cdot 8)$ \\
Co-trimoxazole & $61.7(18.0)$ & $48.0(18 \cdot 4)$ & $59.3(20 \cdot 0)$ \\
Placebo & $60.8(19.6)$ & $49.2(19.7)$ & $57.9(20 \cdot 0)$ \\
\hline
\end{tabular}

* No flare-up of complaints or use of antibiotics occurred in the six weeks before the study.

Table 2 Mean slopes of increase in PEF \% predicted per day and their 95\% confidence levels 14 days after the start of the exacerbation

\begin{tabular}{lll}
\hline Treatment group & Mean & $95 \%$ CI \\
\hline Amoxicillin & 0.58 & 0.27 to 0.89 \\
Co-trimoxazole & 0.78 & 0.22 to 1.34 \\
Placebo & 0.34 & 0.00 to 0.73 \\
\hline
\end{tabular}



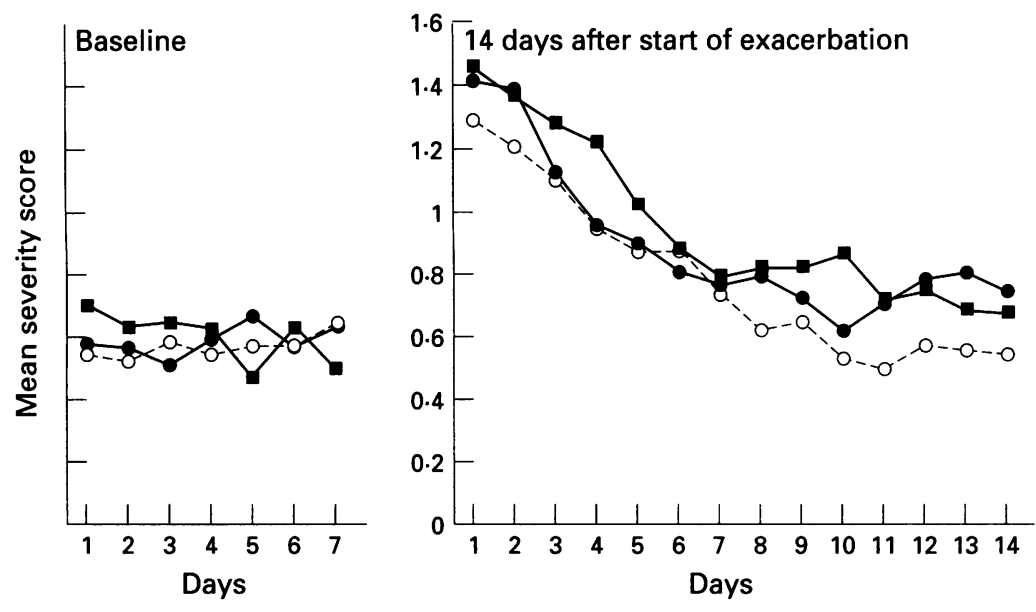

Figure 2 Severity of symptoms during baseline and 14 days after exacerbation. $=$ Amoxicillin $(n=22) ; \square=$ co-trimoxazole $(n=18) ; O=$ placebo $(n=17)$; all administered in combination with prednisolone.

Table 3 Mean (SD) symptom severity scores (\%) in the three treatment groups

\begin{tabular}{llll}
\hline Treatment groups & $\begin{array}{l}\text { Mean of } 7 \text { day } \\
\text { baseline period }\end{array}$ & Day 1 & Day 14 \\
\hline Amoxicillin & $0.56(0.46)$ & $1.42(0.70)$ & $0.75(0.68)$ \\
Co-trimoxazole & $0.60(0.49)$ & $1.46(0.66)$ & $0.68(0.60)$ \\
Placebo & $0.57(0.48)$ & $1.29(0.49)$ & $0.54(0.43)$ \\
\hline
\end{tabular}

* No flare-up of complaints or use of antibiotics occurred in the six weeks before the study.

\section{Symptom scores}

Each symptom showed a similar change for all three treatment groups. Since a positive correlation was found between the underlying symptom scores, a mean symptom severity score was computed. The reliability coefficient for this symptom severity score was $0 \cdot 70$ (Cronbach's alpha). The daily recorded mean severity scores during baseline and the 14 days after the start of an exacerbation of the 22 patients in the amoxicillin group, 18 patients in the co-trimoxazole group, and 17 patients in the placebo group who returned their registration forms are presented in fig 2 .

The mean symptom scores during baseline, at the start of an exacerbation, and at day 14 are presented in table 3 . The values on the start day were significantly different from the mean baseline values $(p<0.001)$. Symptom scores were similar between the three groups when expressed as slopes or absolute values from days 1 to 14 (table 4 ).

The decrease of the symptom severity scores was significant in all three groups $(p<0.001)$. Symptom severity scores decreased by 0.05 $(0.05)$ points per day in the groups receiving

Table 4 Estimated slopes and their associated 95\% confidence intervals of the decrease in symptom severity scores* 14 days after the start of the exacerbation

\begin{tabular}{lll}
\hline Treatment group & Mean & $95 \%$ CI \\
\hline Amoxicillin & -0.05 & -0.07 to -0.02 \\
Co-trimoxazole & -0.06 & -0.08 to -0.04 \\
Placebo & -0.06 & -0.08 to -0.04 \\
\hline
\end{tabular}

* Daily record during a two week period on a four point scale of severity ranging from 0 to 3 of (1) wheeze or dyspnoea (2) cough with mucus production; (3) cough without mucus production; and (4) awakening with complaints of dyspnoea. antibiotics, and by $0.06(0.045)$ points per day in the placebo group.

\section{Temperature}

There was no significant increase in sublingual temperature in the exacerbation period.

\section{Investigation of sputum}

Fifty of the 71 patients (70\%) with an exacerbation produced sputum. Potentially pathogenic microorganisms were isolated from 24 of $50(48 \%)$ of the samples, whereas 19 of $50(38 \%)$ samples had a purulent appearance. On days 7,21 , and 35 after onset of the exacerbation there were four sputum samples which were purulent, irrespective of the medication given.

During the exacerbation eight of $50(16 \%)$ patients produced sputum with evidence of a lower respiratory tract infection that met the requirements of $\geqslant 10^{5}$ potentially pathogenic microorganisms in culture in association with $\geqslant 25$ leucocytes and $<5$ epithelial cells in Gram stain. Two of these patients produced mucoid sputum and six purulent sputum. Two of the latter six received placebo treatment and four antibiotics. In the sputum samples of the two placebo treated patients one showed no potentially pathogenic microorganisms during the follow up period while the other did not return for follow up.

\section{Treatment failures}

Six out of 71 patients $(8 \cdot 5 \%)$ consulted with their physician again within 4-24 days of the start of treatment because of worsening of symptoms. All received an antibiotic. These six patients were equally distributed among the three randomisation groups. Two of these patients, one in the amoxicillin group and one in the placebo group, had a second exacerbation 4-7 days after starting treatment. No potentially pathogenic microorganisms were found in cultures of either sputum sample.

\section{Possible confounding variables}

The patients with asthma were not concentrated in any particular group. Three out of 10 patients with asthma entered the amoxicillin group, three the co-trimoxazole group, and four were in the placebo group. At the onset of their exacerbation PEF \% predicted was significantly higher in asthmatic patients than in those with COPD, but there were no differences in recovery rates. Symptom scores were comparable at the onset of exacerbation, but improved faster in individuals with asthma than in those with COPD.

The distribution of individuals with purulent or non-purulent sputum samples in the three medication regimens was: eight of 12 patients in the amoxicillin group, four of nine in the co-trimoxazole group, and seven of 10 patients in the placebo group.

No significant difference was found between patients with asthma or COPD in the as- 
Table 5 Association of possible confounding variables with percentage predicted peak expiratory flow (PEF) and symptom scores

\begin{tabular}{|c|c|c|c|c|}
\hline \multirow[b]{2}{*}{$\begin{array}{l}\text { Possible confounding } \\
\text { variables }\end{array}$} & \multicolumn{2}{|c|}{ PEF (\% pred) } & \multicolumn{2}{|c|}{ Symptom scores* } \\
\hline & $\begin{array}{l}\text { Day } 1 \text { of an } \\
\text { exacerbation }\end{array}$ & $\begin{array}{l}\text { Recovery } \\
\text { rate }\end{array}$ & $\begin{array}{l}\text { Day } 1 \text { of an } \\
\text { exacerbation }\end{array}$ & $\begin{array}{l}\text { Recovery } \\
\text { rate }\end{array}$ \\
\hline $\begin{array}{l}\text { Asthma/COPD } \\
\text { Smokers, ex-smokers and non-smokers } \\
\text { Purulence/mucoid }\end{array}$ & $\begin{array}{l}\mathrm{p}=0.005 \\
\mathrm{NS} \\
\mathrm{NS}\end{array}$ & $\begin{array}{l}\text { NS } \\
\text { NS } \\
\text { NS }\end{array}$ & $\begin{array}{l}\text { NS } \\
\text { NS } \\
\text { NS }\end{array}$ & $\begin{array}{l}<0 \cdot 05 \\
\text { NS } \\
\text { NS }\end{array}$ \\
\hline
\end{tabular}

NS = not significant.

${ }^{*}$ Daily record during a two week period on a four point scale of severity, ranging from 0 to 3 of (1) wheeze or dyspnoea; (2) cough with mucus production; (3) cough without mucus production; and (4) awakening with complaints of dyspnoea.

sociation of smoking habits or macroscopic appearance of sputum samples with the PEF $\%$ predicted values and symptom scores (table 5).

\section{Discussion}

Our data show that recovery from an exacerbation of asthma or COPD in ambulatory patients when treated by their own general practitioner is not accelerated by adding antibiotics to a short course of oral corticosteroids. Each medication regimen produced comparable improvements in symptom scores, PEF values, and number of treatment failures. When symptoms were analysed in more detail no differences were observed for sputum production or its purulence, and comparable treatment failures were observed in all three groups.

Our results do not confirm the observation by Anthonisen et al that antibiotics contribute to the prevention of health deterioration. ${ }^{6}$ This is probably due to patient selection, since the average frequency of exacerbation was 1.3 per year in their study while in our study it was 0.6 per year. We only included patients treated on an ambulatory basis by their general practitioner, thus excluding more severe exacerbations. The percentage of patients with sputum production at baseline and during exacerbations was $84 \%$ and $81 \%$ in the study by Anthonisen et al and $34 \%$ and $70 \%$ respectively in our study, while the percentage of patients with a mucopurulent or purulent appearance of the sputum during exacerbation in their study was at least $60 \%$ and only $27 \%$ in our study. Anthonisen et al stated that, even though the underlying cause of exacerbations was unknown, antibiotics were justified for increased dyspnoea, sputum production, and purulence. Our results in less severely ill patients show that the use of antibiotics is redundant when corticosteroids are given, irrespective of the presence of potentially pathogenic microorganisms in sputum samples in high concentrations. Combining the two antimicrobial limbs did not alter our results, the rate of recovery being comparable to the placebo group. Patient characteristics of the 16 patients who did not record their PEF values (14 of them did not record their symptom severity scores) were similar to the remaining $\mathbf{5 5}$ patients. It is therefore unlikely that inclusion of these patients would significantly alter the outcome of our study.

During recovery after an exacerbation purulence of the sputum improved independently of the antibiotic treatment, supporting the hypothesis that Gram stain and culture, interpreted on the basis of Bartlett and others, ${ }^{222329}$ do not necessarily indicate ongoing bacterial infection.

The number of exacerbations in this study is too small to draw conclusions concerning the clinical relevance of the change in sputum flora induced by antimicrobial intervention consequently leading to a second exacerbation. ${ }^{332-35}$

Since our definition of an exacerbation may, as in all previous studies, provide an opening for incorrect interpretations, it remains a weak point in every study design. Nevertheless, our results stress the fact that an exacerbation is not synonymous with bacterial infection.

This is the first study of an exacerbation in patients with asthma or COPD who are normally treated by a general practitioner. When symptom scores, PEF values, sublingual temperature, and sputum cultures were monitored, no differences in recovery rates were observed when antibiotics were added to a short course of prednisolone. Thus, bacterial infection of the lower airways is rarely the cause or consequence of symptoms and signs of an increase in airways limitation during an exacerbation. Treatment with prednisolone alone appears to be sufficient in ambulatory general practice patients with mild to moderate obstructive airways disease to eliminate the bronchial obstruction. Diminishing the inflammatory process is probably sufficient. However, these results should not be extrapolated to patients with more severe forms of obstructive airways disease.

We are indebted to Dr J A M Snijder, Director of the Regional Public Health Laboratory of Groningen for use of his laboratory facilities, and especially to Professor Dr D S Postma for reading the manuscript and giving her editorial advice. We wish to thank J P Schouten from the Department of Epidemiology and Statistics of the University of Groningen for his statistical advice. Furthermore, we gratefully acknowledge the participating general practitioners, their assistants, and the patients for their continuous support and enthusiasm in providing us with data and samples.

This study was supported by Grant [7-151-32] from the Netherlands Organisation for Scientific Research (NWO).

1 Elmes PC, Knox K, Fletcher CM. Sputum in chronic bronchitis: effects of antibiotics. Lancet 1953;ii:903-6.

Billas A. Lower respiratory tract infections. Infect Dis 1990; 17:811-24.

3 Van Saene HKF, Willems FTC, Davies RJ. The abnormal carrier state and superinfection following antibiotic treatment of respiratory tract infection in general practice:
clinical, controlled trial. Eur Respir Rev 1991;2:193-8.

clinical, controlled trial. Eur Respir Rev 1991;2:193-8.
4 Hudgel DW, Langston L, Selner JC, McIntosh K. Viral and bacterial infections in adults with chronic asthma. Am Rev Respir Dis 1979;120:393-7.

5 Tager I, Speizer FE. Role of infection in chronic bronchitis. $N$ Engl $\mathcal{F}$ Med 1975;292:563-9.

6 Anthonisen NR, Manfreda J, Warren CPW, Hershfield ES, Harding GKM, Nelson NA. Antibiotic therapy in exacerbations of chronic obstructive pulmonary disease. Intern Med 1987;106:196-204.

7 Editorial. Antibiotics for exacerbations of chronic bronchitis? Lancet 1987;ii:23-4.

8 Chodosh S. Acute bacterial exacerbations in bronchitis and asthma. Am ₹ Med 1987;82:154-63.

9 Nicotra MB, Rivera M, Awe RJ. Antibiotic therapy of acute exacerbations of chronic bronchitis. A controlled study exacerbations of chronic bronchitis. A controlled
using tetracycline. Ann Intern Med 1982;97:18-21.

10 Murphy TF, Sethi S. Bacterial infection in chronic obstructive pulmonary disease. Am Rev Respir Dis 1992;146: 1067-83.

11 Pines A, Raafat H, Plucinski K, Greenfield JSB, Solari M. Antibiotic regimens in severe and acute purulent exacerbations of chronic bronchitis. BMF 1968;2:735-8.

12 Pines A, Raafat H, Greenfield JSB, Linsell WD, Solari ME. Antibiotic regimens in moderately ill patients with purulent exacerbations of chronic bronchitis. $\mathrm{Br} \mathcal{F} \mathrm{Dis}$ Chest 1972;66:107-15. 
13 Pines A. Trimethoprim-sulfamethoxazole in the treatment and prevention of purulent exacerbations of chronic bronchitis. F Infect Dis 1973;128:706-9.

14 Elmes PC, King TKC, Langlands JHM, Mackay JA, Wallace WFM, Wade OL, et al. Value of ampicillin in the hospital treatment of exacerbations of chronic bronchitis. BMF treatment of $1965 ; 2: 904-8$.

15 Berry DG, Fry J, Hindley CP, Hodson JM, Horder EJ, Horder JP, et al. Exacerbations of chronic bronchitis treatment with oxytetracycline. Lancet 1960;i:137-9.

16 Anderson G, Jariwalla AG, Saour J. A comparison of ampicillin and amoxicillin in acute and chronic bronchitis. Thorax 1979;34:814-6.

17 Basran GS, Joseph J, Abbas AMA, Hughes C, Tillotson GS. Treatment of acute exacerbations of chronic obstructive airways disease: a comparison of amoxicillin and ciprofloxacin. $\mathcal{F}$ Antimicrob Chemother 1990;26:19-24.

18 Chodosh S, Eichel B, Ellis C, Medici TC. Comparison of trimethoprim-sulfamethoxazole with ampicillin in acute infectious exacerbations of chronic bronchitis: a doubleinfectious exacerbations of chronic bronchitis: a double
blind crossover study. Rev Infect Dis 1982;4:517-27.

19 Tomson CRV., Veale D, Gould K. Antibiotic policy and infective exacerbation of obstructive airways disease. Lancet 1987;ii:45.

20 Chodosh S. Sputum evaluation - why, when, how and by whom? In: Brody JS, Snider GL, eds. Current topics in the management of respiratory diseases. Ist edn. New York: Churchill Livingstone, 1985;123-45.

21 Nunn AJ, Gregg I. New regression equations for predicting peak expiratory flow in adults. BMF 1989;298:1068-70.

22 Bartlett JG, Finegold SM. Bacteriology of expectorated sputum with quantitative culture and wash technique compared to transtracheal aspirates. Am Rev Respir Dis 1978;117:1019-27.

23 Murray PR, Washington JA. Microscopic and bacteriologic analysis of expectorated sputum. Mayo Clin Proc 1975;50: 339-44.

24 Jordan GW, Wong GA, Hoeprich PD. Bacteriology of the lower respiratory tract as determined by fibre-optic bron- choscopy and transtracheal aspiration. $\mathcal{F}$ Infect Dis 1976; 134:428-35.

25 Sachs APE, van der Waaij D, Groenier KH, Koëter GH, Schiphuis J. Oropharyngeal flora in asthma and in chronic obstructive pulmonary disease. Am Rev Respir Dis 1993; 148:1302-7.

26 Mulder J. Bacteriological examination of sputum in cases of acute and chronic bronchitis. In: Orie NGM, Sluiter HJ, eds. Bronchitis. Assen, Netherlands: Royal van Gorcum, 1961:15-8.

27 Mulder J. Bacteriology of bronchitis. I Chronic bronchitis. Proc $R$ Soc Med 1956;49:773-5.

28 Holloway Y, Boersma WG, Kuttschrütter H, Snijder JAM. Impact of washing sputum on Streptococcus pneumonia and other microorganisms. F Infect Dis 1992;165:397-8.

29 Heineman HS, Chawla JK, Lofton WM: Misinformation from sputum cultures without microscopic examination. f Clin Microbiol 1977;6:518-27.

30 Matthews JNS, Altman DG, Campbell MJ, Royston P. Analysis of serial measurements in medical research. BMF 1990;300:230-5.

31 Dixon WJ. BMDP Statistical software manual, Vol 2. Berkeley: University of California Press, 1992:1311-52.

32 Trigg CJ, Wilks M, Herdman MJ, Clague JE, Tabaqchali $S$, Davies RJ. A double-blind comparison of the effects of cefaclor and amoxicillin on respiratory tract and oropharyngeal flora and clinical response in acute exacerbations of bronchitis. Respir Med 1991;85:301-8.

33 Johanson WG, Pierce AK, Sanford JP, Thomas GD. Nosocomial respiratory infections with Gram negative bacilli: the significance of colonization of the respiratory tract. the significance of colonization
Ann Intern Med 1972;77:701-6.

34 Tillotson JR, Finland M. Bacterial colonization and clinical superinfection of the respiratory tract complicating antibiotic treatment of pneumonia. $\mathcal{F}$ Infect Dis 1969;119:597-624.

35 Ortqvist A, Hammers-Buggren S, Kalin M. Respiratory tract colonization and incidence of secondary infection during hospital treatment of community-acquired pneumonia. Eur f Clin Microbiol Infect Dis 1990;9:725-31. 